\title{
Establishment and Characterization of Human Peripheral Nerve Microvascular Endothelial Cell Lines: A New in vitro Blood-Nerve Barrier (BNB) Model
}

\author{
Masaaki Abe', Yasuteru Sano ${ }^{1}$, Toshihiko Maeda ${ }^{1}$, Fumitaka Shimizu${ }^{1}$, Yoko Kashiwamura', \\ Hiroyo Haruki ${ }^{1}$, Kazuyuki Saito ${ }^{2}$, Ayako Tasaki ${ }^{1}$, Motoharu Kawai ${ }^{1}$, Tetsuya Terasaki ${ }^{3}$, and \\ Takashi Kanda ${ }^{{ }^{*}}$ \\ ${ }^{1}$ Department of Neurology and Clinical Neuroscience, Yamaguchi University Graduate School of Medicine, \\ 1-1-1 Minamikogushi, Ube, Yamaguchi 755-8505, Japan, ${ }^{2}$ Department of Neurology and Neurological \\ Science, Tokyo Medical and Dental University Graduate School, 1-45-45 Yushima, Bunkyo-ku, Tokyo 113- \\ 8519, Japan, ${ }^{3}$ Department of Molecular Biopharmacy and Genetics, Graduate School of Pharmaceutical \\ Sciences, Tohoku University, Aoba, Aramaki, Aoba-ku, Sendai, Miyagi 980-8578, Japan
}

\begin{abstract}
The blood-nerve barrier (BNB) is a highly specialized unit that maintains the microenvironments of the peripheral nervous system. Since the breakdown of the BNB has been considered a key step in autoimmune neuropathies such as Guillain-Barré syndrome and chronic inflammatory demyelinating polyraduculoneuropathy, it is important to understand the cellular properties of the peripheral nerve microvascular endothelial cells (PnMECs) which constitute the BNB. For this purpose, we established an immortalized cell line derived from human PnMECs. The human PnMECs were transduced with retroviral vectors encoding the temperaturesensitive SV40 large T antigen and human telomerase. This cell line, termed FH-BNB, showed a spindle fibershaped morphology, expression of von Willebrand factor and uptake of acetylated low density lipoprotein. These cells expressed tight junction proteins including occludin, claudin-5, ZO-1 and ZO-2 at the cell-cell boundaries. P-glycoprotein and GLUT-1 were also detected by a Western blot analysis and the cells exhibited the functional expression of p-glycoprotein. In addition, transendothelial electrical resistance experiments and paracellular permeabilities of sodium fluorescein and fluorescein isothiocyanate-labeled dextran of molecular weight $4 \mathrm{kDa}$ across these cells demonstrated that FH-BNBs had functional tight junctions. These results indicated that FHBNBs had highly specialized barrier properties and they might therefore be a useful tool to analyze the pathophysiology of various neuropathies.
\end{abstract}

Key words: blood-nerve barrier/endothelial cell lines/tight junction/transporter/claudin-5

\section{Introduction}

The blood-nerve barrier (BNB) serves as a functional and structural unit protecting the nervous system from circulating blood (Poduslo et al., 1994). The BNB comprises the endoneurial microvasculature and the innermost layers of the perineurium. The perineurium is composed of flattened cells derived from fibroblasts, and these cells form several layers (Weerasuriya, 2005). Additionally, both sides of the perineurium are surrounded by basement membrane, and

\footnotetext{
*To whom correspondence should be addressed: Takashi Kanda, Department of Neurology and Clinical Neuroscience, Yamaguchi University Graduate School of Medicine, 1-1-1 Minamikogushi, Ube, Yamaguchi 755-8505, Japan.

Tel: +81-836-22-2714, Fax: +81-836-22-2364

E-mail: tkanda@yamaguchi-u.ac.jp
}

the perineurium is thought to be a specialized type of connective tissue (Weerasuriya, 2005). Many studies (Soderfeldt, 1974; Boddingius, 1984; Weerasuriya and Rapoport, 1986; Weerasuriya et al., 1989) have demonstrated that the perineurium shows much lower permeability against many substances than endoneurial microvessels. Hence, the peripheral nerve microvascular endothelial cells (PnMECs) constituting the microvessels in the endoneurium can be considered to be the main interface between the blood and peripheral nerves. It has recently been reported that disruptions and permeability changes in the endoneurial microvessels play a crucial role in many autoimmune disorders of the peripheral nervous system including Guillain-Barré syndrome, chronic inflammatory demyelinating polyradiculoneuropathy (CIDP), and paraproteinemic neuropathy (Lach et al., 1993; Kanda et al., 
1994, 2000, 2004). Because PnMECs constitute the bulk of the $\mathrm{BNB}$, in vitro studies using cultured PnMECs could be very useful to obtain a better understanding of the pathophysiology of these peripheral nerve disorders. However, only a few in vitro BNB models have been reported so far (Argall et al., 1994; Kanda et al., 1997; Iwasaki et al., 1999; Sano et al., 2007). This is probably due to the technical difficulties in isolating PnMECs from a peripheral nerve.

Transgenic rats harboring a temperature-sensitive SV40 large T-antigen gene (tsA58) have recently been developed as a source of conditionally immortalized cell lines (Takahashi et al., 1999). Cultured cells derived from these animals can be easily immortalized by activating the tsA58 gene at a permissive temperature of $33^{\circ} \mathrm{C}$ and can have in vivo functions at a non-permissive temperature of 37 or $39^{\circ} \mathrm{C}$ (Takahashi et al., 1999; Hosoya et al., 2000). Human PnMECs expressing the tsA58 gene could have the potential to be used in studies elucidating their role in many diseases affecting the human peripheral nervous system. Recently, we established a conditionally immortalized PnMEC cell line derived from a human sciatic nerve and analyzed the effects of hydrocortisone on these endothelial cells (Kashiwamura et al., 2011). However, the barrier properties of this cell line have not been fully characterized.

The purpose of the present study was to establish a conditionally immortalized human peripheral nerve microvascular endothelial cell line. O'Hare et al. reported that transgenic expression of the catalytic subunit of human telomerase (hTERT) in combination with the temperaturesensitive SV40 large T-antigen is necessary to immortalize human endothelial cells of different peripheral organs (O'Hare et al., 2001). We therefore immortalized human PnMECs through coexpression of hTERT and tsA58 using retroviral vector systems, and investigated the barrierspecific properties of this novel in vitro BNB model.

\section{Materials and Methods}

\section{Materials}

Polyclonal anti-occludin, anti-Zonula occludens-1 (ZO-1), and anticlaudin-5 antibodies were obtained from Zymed (San Fransisco, CA, U.S.A.). The monoclonal anti-p-glycoprotein (p-gp) antibody was obtained from Signet Laboratories (Dedham, MA, U.S.A.). The polyclonal anti-Zonula occludens-2 (ZO-2) and anti-von Willebrand factor (vWF) antigen antibodies were from Santa Cruz Biotechnologies (Santa Cruz, CA, U.S.A.). The polyclonal antihuman catalytic unit of telomerase (hTERT) antigen antibodies was obtained from Rockland Immunochemicals, Inc (Gilbertsville, PA, U.S.A.). The monoclonal anti-SV40 T antigen antibody was purchased from Calbiochem (Darmstadt, Germany). Fluorescein isothiocyanate (FITC)-conjugated secondary antibodies were purchased from Zymed. The retrovirus vector pDON-AI was from TAKARA Bio Inc (Otsu, Japan). Rhodamine123, sodium fluores- cein and FITC-labeled dextran of molecular weight $4 \mathrm{kDa}$ were purchased from Sigma (St. Louis, MO, U.S.A.). Calceinacetoxymethylester (calcein-AM) was obtained from Molecular Probes (Eugene, OR, U.S.A.). Verapamil was purchased from WAKO (Osaka, Japan). Human umbilical vein endothelial cells (HUVECs), HEK293 cells and HL-60 cells were obtained from Japan Health Sciences Foundation (Osaka, Japan).

\section{Culture media}

The endothelial cell (EC) growth medium contained EBM-2 medium (Cambrex, Walkersville, MD, U.S.A.) supplemented with $20 \%$ fatal bovine serum (FBS) (Highclone, Logan, UT, U.S.A.), EGM-2 MV (Cambrex), $100 \mathrm{U} / \mathrm{ml}$ penicillin (Sigma), $100 \mu \mathrm{l} / \mathrm{ml}$ streptomycin (Sigma), and $25 \mathrm{ng} / \mathrm{ml}$ amphotericin B (Sigma).

\section{Isolation of human peripheral nerve microvascular endothelial cells forming the $\mathrm{BNB}$}

The study protocol for human peripheral nerve tissue was approved by the ethics committee of the Medical Faculty, Yamaguchi University and was conducted in compliance with the Declaration of Helsinki, as amended in Somerset West in 1996. Tissue samples were obtained from an adult female who died of a heart failure. Written informed consent was obtained from the patient's family before the study. PnMECs were isolated in accordance with a previously described procedure (Kanda et al., 1997) with modification. Briefly, the sciatic nerve was removed from the patient, that the epi- and perineuria were carefully stripped off with fine forceps, mimicking the teased fiber preparation for the peripheral nerve pathology. Next, the endoneurium was finely minced with a razor blade and digested with $0.25 \%$ collagenase type I (Sigma) in $1 \times$ Hanks' balanced salt solution (HBSS) (Invitrogen) at $37^{\circ} \mathrm{C}$ for $2 \mathrm{hr}$ in a shaking water bath. After centrifugation $(800 \mathrm{~g}$, $5 \mathrm{~min}$ ), the pellet was suspended in $15 \%$ dextran solution, followed by centrifugation for $10 \mathrm{~min}$ at $4{ }^{\circ} \mathrm{C}$ and $5,000 \mathrm{~g}$. The pellet was washed and incubated in a type I collagen-coated dish (Iwaki, Chiba, Japan) at $37^{\circ} \mathrm{C}$ in a humidified atmosphere of $5 \% \mathrm{CO}_{2}$ and $95 \%$ air.

\section{Immortalization and purification of PnMECs}

After 4 days from the first dissemination, cells were incubated overnight with $\mathrm{pDON}-\mathrm{AI} / \mathrm{tsA} 58$, a retroviral vector encoding the open reading frame of the temperature-sensitive SV40 large T antigen. Twelve hours after the beginning of the incubation, cells were washed with HBSS and were subsequently grown at $33^{\circ} \mathrm{C}$. This was followed by another overnight incubation with pDON-AI/ hTERT, a retroviral vector encoding the open reading frame of hTERT. After the incubation, cells were washed with HBSS and processed for an additional incubation at $33^{\circ} \mathrm{C}$. After endothelial cells (ECs) had proliferated sufficiently for cloning, they were picked up with a cloning cup. As the ECs grew, non-ECs such as pericytes, fibroblasts, and Schwann cells also appeared and gradually began to occupy the culture area of the dish. These non-ECs 
were scratched and removed mechanically with a sterilized pointed rubber policeman. After several passages (passage 4) for cloning, some clonal populations that consisted of pure endothelial cells were obtained. We selected one clonal cell line which stably proliferated, and designated these cells as "FH-BNBs". These FHBNBs showed immortality at a permissive temperature of $33^{\circ} \mathrm{C}$.

\section{Uptake of Dil-Ac-LDL}

To label FH-BNBs with 1,1'-dioctacecyl-3,3,3',3', tetramethyl indocarbocyanine perchlorate acetylated low-density lipoprotein (Dil-Ac-LDL) (Biogenesis, Poole, UK), cells were incubated with $10 \mu \mathrm{g} / \mathrm{ml}$ Dil-Ac-LDL at $33^{\circ} \mathrm{C}$ in culture medium overnight. The cells were subsequently viewed under a fluorescence microscope (Olympus, Tokyo, Japan). The PnMECs had incorporated bright Dil-Ac-LDL particles into their cytoplasm. Human brain pericyte cell lines which did not take up Dil-Ac-LDL (Shimizu et al., 2011) was used as a negative control.

\section{Cell growth study}

To determine the doubling time of the FH-BNBs, $5.0 \times 10^{4}$ cells were seeded on type I collagen-coated $35-\mathrm{mm}$ dishes and grown at 33 and $37^{\circ} \mathrm{C}$. After a predetermined period, the cells were trypsinized and counted using a hemocytometer.

\section{Immunoytochemistry}

The confluent cultured cells were washed twice in PBS. For von Willebrand factor immunocytochemistry, cells were fixed in $4 \%$ paraformaldehyde (Wako, Osaka, Japan) for $15 \mathrm{~min}$ at room temperature. Next, cells were permeabilized with $0.1 \%$ Triton X-100 (Sigma) for $10 \mathrm{~min}$ and then blocked with $1 \% \mathrm{FBS}$ in PBS for $1 \mathrm{hr}$. The cells were fixed in $100 \%$ methanol for $20 \mathrm{~min}$ at $-20^{\circ} \mathrm{C}$ for hTERT immunocytochemistry, were washed three times in PBS, and blocked with $1 \%$ FBS. For the staining of claudin-5, ZO-1 and $\mathrm{ZO}-2$, cells were fixed with $100 \%$ ethanol for $30 \mathrm{~min}$ at $4{ }^{\circ} \mathrm{C}$, washed three times in PBS, permeabilized with $1 \%$ Triton X-100 for $20 \mathrm{~min}$ at room temperature, washed in PBS, and blocked with $2 \%$ FBS before staining. For the occludin staining, the cells were fixed with acetone and methanol mixed $1: 1$ for $10 \mathrm{~min}$ at $4{ }^{\circ} \mathrm{C}$, washed three times in PBS, and blocked with $2 \%$ FBS. After several washes with PBS, cells were incubated with the relevant antibodies (1:50 dilution) at $4^{\circ} \mathrm{C}$ overnight. Cells were subsequently washed with PBS and then incubated with FITC-conjugated secondary antibodies (1:200 dilutions) for $1 \mathrm{hr}$ at room temperature. HUVECs were used as a negative cotrol for hTERT staining. Human brain pericyte cell lines were used as a negative control (Shimizu et al., 2011). The nuclei were stained with DAPI, and fluorescence was detected using a fluorescence microscope (Olympus).

\section{Transendothelial electrical resistance (TEER) studies}

The transwell inserts (pore size, $0.4 \mu \mathrm{m}$; effective growth area, 30 $\mathrm{mm}^{2}$; BD Bioscience, NJ, U.S.A.) were coated with rat tail collagen type-I (BD Bioscience) in accordance with the manufacturer's directions. Cells were seeded at $1.0 \times 10^{4}$ cells/insert, on these collagen-coated culture inserts and were incubated at $33^{\circ} \mathrm{C}$. After attaching themselves and becoming confluent on the bottom of the insert (24-48 hr), the TEER of cell layers was measured using a Millicell electrical resistance apparatus (Endohm-6 and EVOM, World Precision Instruments, Sarasota, FL, U.S.A.). TY08 cells, which are immortalized human brain microvascular endothelial cells that have functional tight junctions (Sano et al., 2010) were used as a positive control. TR-BBBs, derived from the tsA58 transgenic rat brain and lacking claudin-5 expression (Ohtsuki et al., 2007) were used as control endothelial cells without sufficient barrier functions. In addition, we mesured the TEER values of FH-BNBs after $3 \mathrm{hr}$ incubation with $4 \mathrm{mM}$ EGTA, which disrupt tight junction barrier (Li et al., 2010). Statistical significance was evaluated using Student's $t$-test.

\section{Reverse transcription-polymerase chain reaction (RT-PCR) analysis}

After reaching confluency, the cells were washed three times with PBS. Total RNA was prepared from PBS-washed cells, human cerebrum and kidney using an RNeasy ${ }^{\circledR}$ Plus Mini kit (Qiagen, Hilden, Germany). RT and PCR amplification were performed with TAKARA PCR Thermal Cycler Dice (Takara, Otsu, Japan). Single-stranded cDNA was synthesized from $250 \mathrm{ng}$ of total RNA using the StrataScript ${ }^{\mathbb{R}}$ First Strand Synthesis System (Stratagene, Ceda Greek, TX, U.S.A.) with an oligo-dT primer, and sequential PCR was carried out with Go $\mathrm{Taq}^{\circledR}$ (Promega). The temperature cycling conditions for each primer consisted of $5 \mathrm{~min}$ at $94^{\circ} \mathrm{C}, 1$ $\min$ at $55-65^{\circ} \mathrm{C}$, and $1 \mathrm{~min}$ at $72^{\circ} \mathrm{C}$, with a final extension for 10 $\min$ at $72^{\circ} \mathrm{C}$. The sequence specificity of each primer pair and its reference, except claudin-12, are shown in Table I. The primers for claudin-12 were designed as follows: sense ctgtttccataggcagagcg and antisense aagcagattcttagccttcc (Accession number NM_012129; fragment size $364 \mathrm{bp}$ ). The PCR products were visualized by ethidium bromide staining following resolution on $2 \%$ agarose gels. Products were compared with a 50-bp ladder (O'GeneRulerTM 50 bp DNA Ladder, Burlington, Canada) to estimate band size. The size of each amplified product corresponded to the expected size described in the literature.

\section{Permeability studies}

FH-BNBs, TY08 cells and TR-BBBs were seeded on 24-well tissue culture inserts $\left(0.4 \mu \mathrm{m}\right.$ pore size, $1.0 \times 10^{4}$ cells/insert $)$, and grown to confluence. The cells were incubated at $37^{\circ} \mathrm{C}$ for $30 \mathrm{~min}$ before the beginning of the experiment. Next, $1,300 \mu \mathrm{l}$ of culture medium were added to the lower well and $500 \mu \mathrm{l}$ of culture medium containing sodium fluorescein $(10 \mu \mathrm{g} / \mathrm{ml})$ and FITClabeled dextran of molecular weight $4 \mathrm{kDa}(1 \mathrm{mg} / \mathrm{ml})$ were added to the upper compartment of each insert. After incubation for 15, 30,45 or $60 \mathrm{~min}$ at $37^{\circ} \mathrm{C}$, the lower chamber was sampled and the fluorescence that passed through the cell-covered inserts was mea- 
Table I. HUMAN PRIMER PAIRS UTILIZED IN RT-PCR ANALYSIS

\begin{tabular}{|c|c|c|c|}
\hline molecule & sense & antisense & reference \\
\hline occludin & 5'-ACCCATCTGATATGTGGAA-3' & 5'-AGGAACCGGCGTGGATTTA-3' & Ghassemifar et al. (2003) \\
\hline claudin-1 & 5'-CTGCCCCAGTGGAGGATTTA-3' & 5'-CAATGACAGCCATCCACATC-3' & Peng et al. (2011) \\
\hline claudin-5 & 5'-CTGTTTCCATAGGCAGAGCG-3' & 5'-AAGCAGATTCTTAGCCTTCC-3' & Varley et al. (2006) \\
\hline claudin-19 & 5'-CTCAGCGTAGTTGGCATGAA-3' & 5'-GAAGAACTCCTGGGTCACCA-3' & Peng et al. (2011) \\
\hline JAM-A & 5'-GACACGGGAAGACACTGGGACA-3' & 5'-ATGCGCACAGCATTTGAAGTCA-3' & Ghassemifar et al. (2003) \\
\hline $\mathrm{ZO}-1$ & 5'-TTTAAGCCAGCCTCTCAACA-3' & 5'-CTGCTGGCTTGTTTCTCTAC-3' & Ghassemifar et al. (2003) \\
\hline $\mathrm{ZO}-2$ & 5'-GCCTACACTGACAATGAGCTGGA-3' & 5'-TTGGGAGCATTATCTTGCTCCTCA-3' & Ghassemifar et al. (2003) \\
\hline GLUT-1 & 5'-TGTCCTATCTGAGCATCGTG-3' & 5'-CTCCTCGGGTCTCTTATCAC-3' & Umeki et al. (2002) \\
\hline MDR-1 & 5'-GCCTGGCAGCTGGAAGACAAATACACAAAATT-3' & 5'-CAGACAGCAGCTGACAGTCCAAGAACAGGACT-3' & Weksler et al. (2005) \\
\hline MRP-1 & 5'-ACCAAGACGTATCAGGTGGCC-3' & 5'-CTGTCTGGGCATCCAGGAT-3' & Weksler et al. (2005) \\
\hline vWF & 5'-CATTGGTGAGGATGGAGTCC-3' & 5'-AGCACTGGTCTGCATTCTGG-3' & Fuchs et al. (2006) \\
\hline G3PDH & 5'-TGAAGGTCGGAGTCAACGGATTTGGT-3' & 5'-CATGTGGGCCATGAGGTCCACCAC-3' & Ye et al. (2003) \\
\hline
\end{tabular}

sured using a MX3000P instrument (Stratagene). The volume cleared was plotted against time, and the slope estimated by a linear regression analysis was used to calculate the PS value for the endothelial monolayer (PeS), as described previously (Sano et al., 2010): $1 / \mathrm{PeS}=1 / \mathrm{P}_{\text {total }} S-1 / \mathrm{P}_{\text {filter }} S$, where $\mathrm{P}_{\text {total }} \mathrm{S}$ and $\mathrm{P}_{\text {filter }} \mathrm{S}$ are the PS values in the presence and absence of cells, respectively. The PeS value was divided by the surface area of the culture insert (30 $\mathrm{mm}^{2}$ ) to give the endothelial permeability coefficient $(\mathrm{Pe})$.

\section{Western blot (WB) analysis}

FH-BNBs and human brain specimens were homogenized in cell lysis buffer containing $50 \mathrm{mM}$ Tris- $\mathrm{HCl}, \mathrm{pH} 7.4,5 \mathrm{mM}$ EDTA, $0.5 \% \mathrm{NP} 40,0.5 \%$ sodium deoxycholate, $150 \mathrm{mM} \mathrm{NaCl}$ and a protease inhibitor cocktail tablet (Roche). Homogenized samples were centrifuged at 5,000 g for $10 \mathrm{~min}$ at $4^{\circ} \mathrm{C}$ and the supernatant was subjected to electrophoresis. Twenty micrograms of protein was fractionated on a $7 \%(\mathrm{p}$-gp), $10 \%(\beta$-actin, SV40 T-antigen and GLUT-1) or $12.5 \%$ (claudin-5) gel and electophoretically transferred onto nitrocellulose membranes. The membrane was blocked at room temperature for $2 \mathrm{hrs}$ with $5 \%$ powdered skimmed milk in PBS containing $0.05 \%$ Tween 20 (PBS-T). After that, the membrane was incubated with a primary antibody in PBS-T and 5\% milk (1:100) at room temperature for $2 \mathrm{hrs}$, followed by incubation with a secondary antibody in PBS-T and 5\% milk (1:2000) for 1 hr. Membranes were extensively washed in PBS-T and visualized by enhanced chemiluminescence detection (ECL-plus, Amersham, UK). TY08 cells that express the SV40 large T antigen and claudin-5 were used as a positive control (Sano et al., 2010). HL60 cells, which do not express claudin-5, were used as a negative control, and were purchased from the Japan Health Sciences Foundation (Osaka, Japan). HEK293 cells, which do not express the SV40 large T antigen, were used as a negative control.

\section{Drug accumulation studies}

Confluent FH-BNBs grown in type I collagen-coated 24-well plates were washed three times with PBS and preincubated for 30 min at $37^{\circ} \mathrm{C}$ in a shaking water bath with or without verapamil $(100 \mu \mathrm{M})$, which is a p-gp efflux transport inhibitor. Next, the cells were incubated in culture medium containing the fluorescent substrates rhodamine $123(10 \mu \mathrm{M})$, a substrate of p-gp and Breast Cancer Resistance Protein (BCRP), or calcein-AM (10 mM), a substrate of p-gp and multi-drug resistance-associated protein 1 (MRP1) with or without verapamil for an hour at $37^{\circ} \mathrm{C}$. The cells were then washed three times with PBS and lysed in $1 \%$ Triton $\mathrm{X}-100$. The amount of fluorescent substrates retained in the cells was detected using a MX3000P instrument (Stratagene).

\section{Results}

\section{Establishment of FH-BNBs}

We successfully established a conditionally immortalized peripheral nerve microvascular endothelial cell line, "FHBNB", which was obtained by transfection with a retrovirus encoding tsA58 and hTERT. FH-BNBs appeared to be closely packed and have spindle fiber-shaped morphology, which has been thought to characterize endothelial cells constituting barrier systems (Hosoya et al., 2000) (Fig. 1A). Endothelial origin with FH-BNB was confirmed by their expression of von Willebrand factor and the uptake of DilAc-LDL, both of which have been reported to be specific markers for endothelial cells (Yamamoto et al., 1998; Voyta et al., 1984). All of these cells were positive for Dil-AcLDL incorporation (Fig. 1A and B). The expression of factor VIII/von Willebrand factor, a specific marker for endothelial cells, on these cells was detected by RT-PCR (Fig. 1C) and immunocytochemical analysis (Fig. 1D). 
A
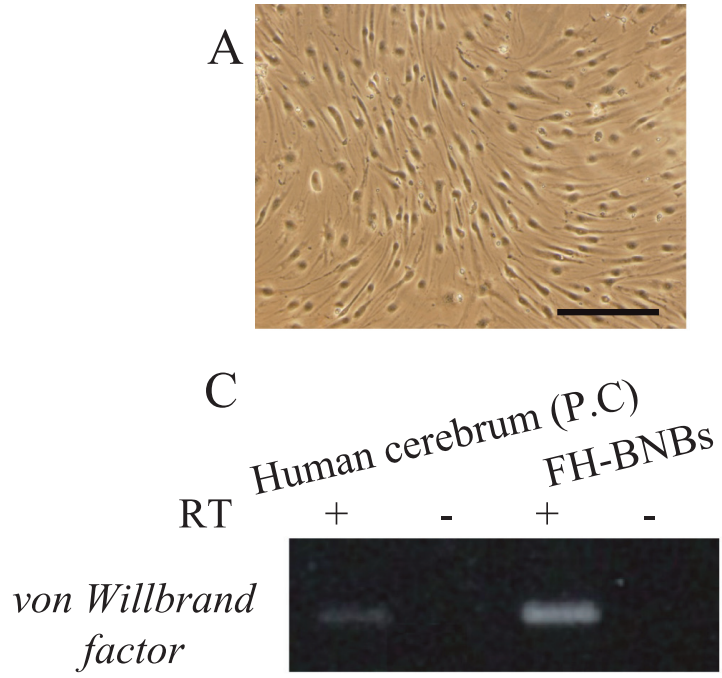

$\mathrm{E}$

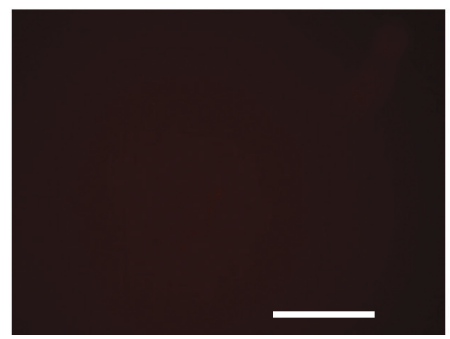

$\mathrm{B}$

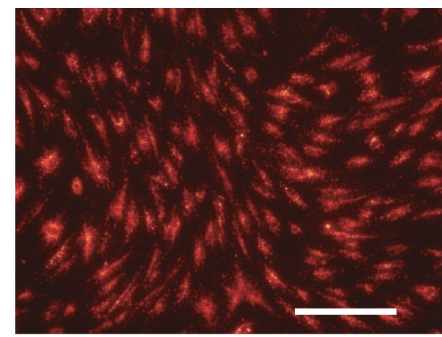

$\mathrm{D}$

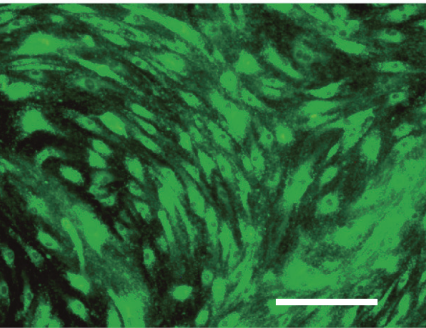

F

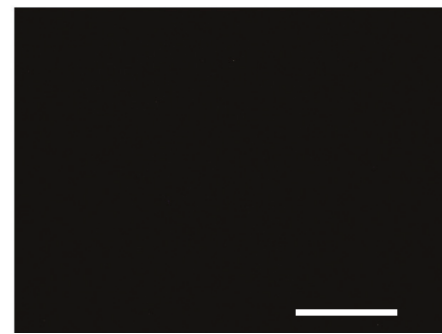

Fig. 1. A phase contrast micrograph of the FH-BNBs (A) and the corresponding fluorescence image after Dil-Ac-LDL uptake (B). The mRNA expression of von Willebrand factor (C) in FH-BNBs determinated by RT-PCR analysis. The reactions were performed against total RNA with (+) or without (-) the RT reaction. Immunostaining of FH-BNBs (D) using an anti-von Willebrand factor antibody. Human brain pericyte cells did not take up Dil-Ac-LDL (E) and express von Willebrand factor $(\mathrm{F})$. The scale bars correspond to $100 \mu \mathrm{m}$.

\section{Expression of tsA 58 and hTERT}

In FH-BNBs, hTERT proteins were found in their nuclei (Fig. 2A and B). In addition, a WB analysis showed that these cells exhibited the large $\mathrm{T}$-antigen with a molecular weight of $94 \mathrm{kDa}$, which was the same molecular weight as that of the TY08 cells used as a positive control (Fig. 2D). After the temperature shift from $33^{\circ} \mathrm{C}$ to $37^{\circ} \mathrm{C}$, the amount of large T-antigen gradually decreased (Fig. 2D). The amount of large-T antigen protein decreased dramatically $48 \mathrm{hrs}$ after the temperature shift. When FH-BNBs were seeded and cultured at $33^{\circ} \mathrm{C}$, they proliferated stably with a doubling time of about 3 days (Fig. 2E) and maintained their spindle shaped morphology for more than 30 passages. However, two days after the temperature shift from 33 to $37^{\circ} \mathrm{C}$, the cell growth arrested and the cells gradually swelled and finally died after a $\sim 7$-day culture (Fig. 2F). These results indicated that FH-BNBs have an obvious temperature sensitive nature and are dissimilar to cell lines expressing both the SV40 T antigen and hTERT.

\section{Expression of tight junction molecules in FH-BNBs}

The expression of claudin-1, claudin-5, claudin-12, junctional adhesion molecule A (JAM-A), ZO-1 and ZO-2 corresponding to tight junction components of endothelial cells forming BBB (Zlokovic, 2008) was verified in FH-BNBs by an RT-PCR analysis (Fig. 3A, B). Claudin-19, which deficient mice induced peripheral nervous system deficits (Miyamoto et al., 2005) was expressed in FH-BNBs, but not in human cerebrum. Claudin-5, the most important barrier protein, was detected by a WB analysis at a molecular weight of $25 \mathrm{kDa}$ (Fig. 3C). In addition, we showed that claudin-5, occludin, ZO-1 and ZO-2 were localized at the cell-cell boundaries in FH-BNBs by an immunohistochemical analysis (Fig. 4A-D).

\section{Expression of transporters and functional expression of p-glycoprotein in FH-BNBS}

The mRNA expression of GLUT-1, MDR1a and MRP1 were detected in FH-BNBs (Fig. 5A). In addition, GLUT-1 with a molecular weight of $55 \mathrm{kDa}$, and p-gp encoded by 
A

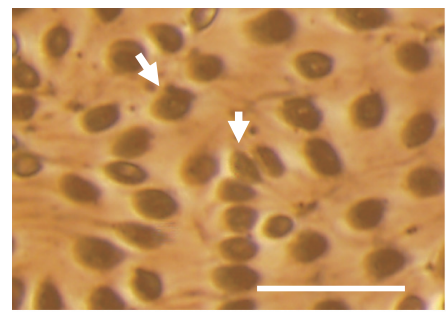

B

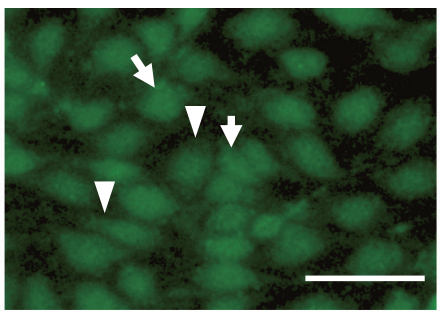

C

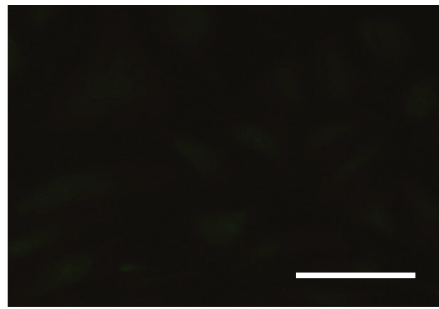

D

(1)

(2)

(3)

(4)

(5)

(6)
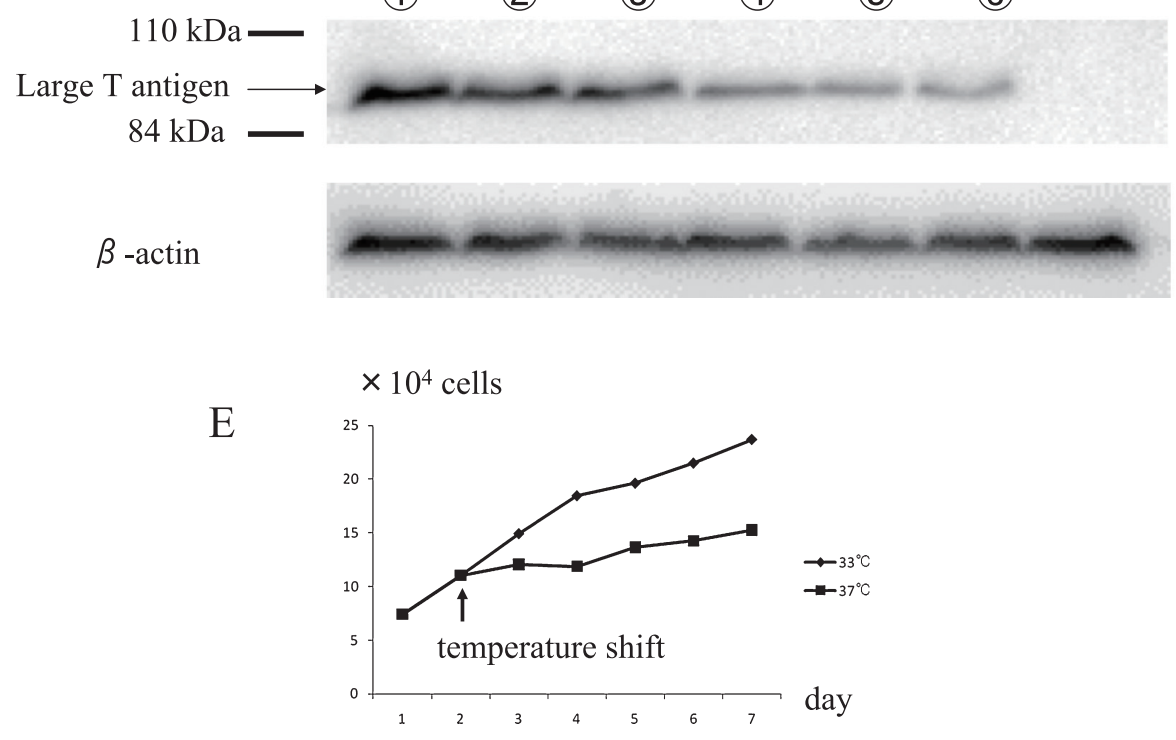

F

Proliferation at $33^{\circ} \mathrm{C}$

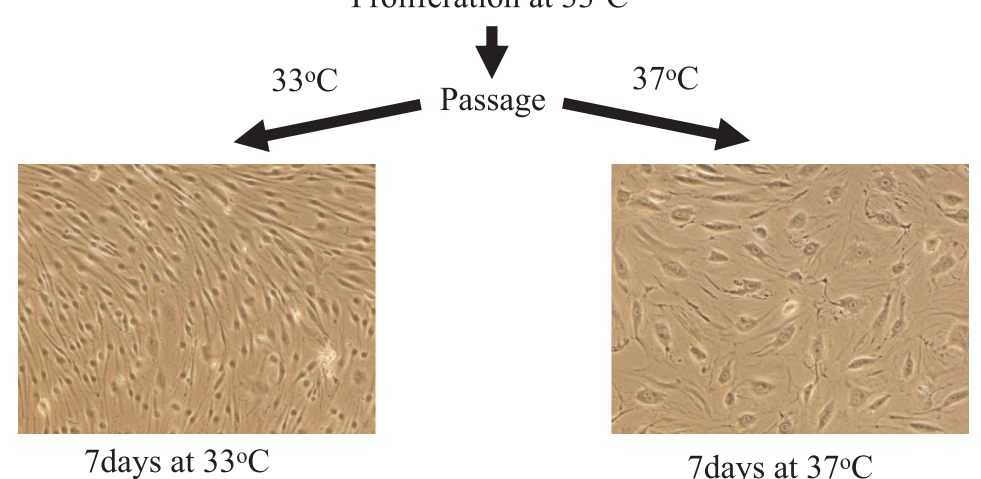

Fig. 2. A phase microscopy image of FH-BNBs (A) and the corresponding immunocytochemical staining using an anti-hTERT antibody (B). Both nuclear (arrow) and perinuclear (arrowhead) hTERT immunoreactivities were detected. HUVECs were used as a negative control for hTERT staining (C). The scale bars indicate $25 \mu \mathrm{m}$. The quantity of tsA58 protein (D) in FH-BNBs at permissive or non-permissive temperature was examined using an anti-SV40 large T antigen antibody. Lane 1, TY08 cells used as a positive control; Lane 2, FH-BNBs cultured at $33^{\circ} \mathrm{C}$; Lane 3, FH-BNBs cultured for 24 hrs at $37^{\circ} \mathrm{C}$; Lane 4 , FH-BNBs cultured for $48 \mathrm{hrs}$ at $37^{\circ} \mathrm{C}$; Lane 5 , FH-BNBs cultured for 3 days at $37^{\circ} \mathrm{C}$; Lane 6 , FH-BNBs cultured for 5 days at $37^{\circ} \mathrm{C}$. The $\mathrm{FH}-\mathrm{BNBs}$ proliferated readily at the permissive temperature of $33^{\circ} \mathrm{C}$; Lane 7, HEK293 cells used as a negative control. (E). About 2 days after the temperature shift to $37^{\circ} \mathrm{C}$, the cell growth was arrested. Each point represents the mean \pm standard deviation $(\mathrm{SD}, \mathrm{n}=3)$. The temperature sensitive nature of FH-BNBs $(\mathrm{F})$. This cell line demonstrated sufficient proliferation at the permissive temperature $\left(33^{\circ} \mathrm{C}\right)$. However, once the cells are spread at the dish at $37^{\circ} \mathrm{C}$, they gradually lose their proliferative capacity and become senescent and enlarged. This morphology resembles non-transfected, primary cultured human PnMECs. 


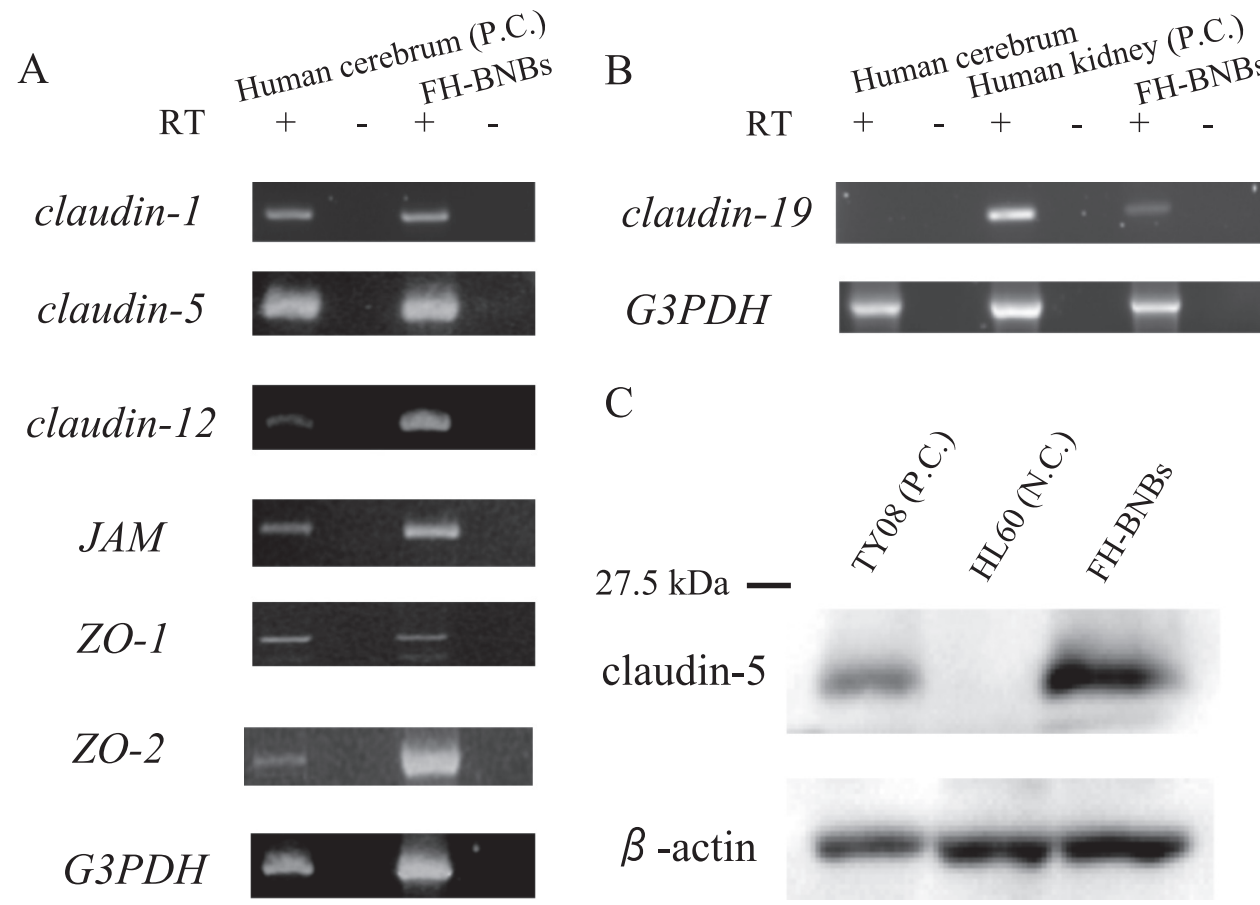

Fig. 3. The RT-PCR analysis of the expression of tight junction molecules in FH-BNBs. The expression of claudin-1, claudin-5, claudin-12, JAM-A, ZO1 and ZO-2 mRNA in human brain specimens (lane 1) and FH-BNBs (lane 2) were verified (A). Claudin-19 mRNA were expressed in human kidney specimens (lane 2) and FH-BNBs (lane 3) but not human cerebrum specimens (lane 1) (B). G3PDH was used as a control. The reactions were performed against total RNA with (+) or without (-) RT. The Western blot analysis of claudin-5 in FH-BNBs (C). Lane 1, TY08 cells used as a positive control; Lane 2, HL-60 cells as a negative control; Lane 3, FH-BNBs.

MDR-1 with a molecular weight of $190 \mathrm{kDa}$, were verified in FH-BNBs at the protein level by a WB analysis (Fig. 5B). Next, the function of p-gp was evaluated in the FH-BNBs. The influence of the $\mathrm{p}$-gp inhibitor verapamil on the uptake of the p-gp substrates rhodamine 123 and calcein-AM in the FH-BNBs was investigated. The inhibition of $\mathrm{p}$-gp by verapamil led to a significantly increased uptake of rhodamine123 (Fig. 6A) and calcein-AM (Fig. 6B). These results therefore showed that the p-gp expressed in the $\mathrm{FH}$ BNBs acted as an efflux pump against the p-gp substrates.

\section{FH-BNBs have functional tight junctions}

Compared with TY08 cells, which express claudin-5 and have functional tight junctions (Sano et al., 2010), FHBNBs demonstrated the similar degrees of the permeability coefficients for sodium fluorescein $(\mathrm{MW}=376 \mathrm{Da}$; $0.60 \pm 0.16$ vs $0.34 \pm 0.03 \times 10^{-3} \mathrm{~cm} / \mathrm{min}$ ) (Fig. 7A) and FITCdextran (MW=4 kDa; $0.34 \pm 0.12$ vs $\left.0.30 \pm 0.09 \times 10^{-3} \mathrm{~cm} / \mathrm{min}\right)$ (Fig. 7B), as well as similar TEER values $(36.3 \pm 4.0$ vs $38.0 \pm 4.4 \Omega . \mathrm{cm}^{2}$ ) (Fig. 7C). In addition, the permeabilities to each of the above compounds were much lower than those of TR-BBBs and the TEER value of FH-BNBs was much higher than that of the TR-BBBs, which have been reported to lose their barrier properties due to a lack of claudin-5 expression (Ohtsuki et al., 2007). The TEER values of FHBNBs incubated with $4 \mathrm{mM}$ EGTA, which disrupt tight junction barrier (Li et al., 2010), decreased and became comparable to those of TR-BBBs (Fig. 7C). These results indicate that FH-BNBs have the same degree of functional tight junctions as TY08 cells.

\section{Discussion}

In this study, we successfully established a human peripheral nerve microvascular endothelial cell line (FH-BNBs). Since primary PnMECs rapidly undergo senescence after a few divisions (Kanda et al., 1997), it is very difficult to establish stable experimental systems using primary cell culture. Usually, oncogenes such as the SV40 large Tantigen, have been used to immortalize human somatic cells like brain microvascular endothelial cells (Stins et al., 2001). However, the SV40 large T-antigen interacts with various proteins such as retinoblastoma and $\mathrm{p} 53$, and these interactions often affect fundamental cellular functions. In fact, one of the endothelial cell lines immortalized by the SV40 large T-antigen did not show contact inhibition, i.e. they demonstrated a tumor-like phenotype (Callahan et al., 2004). To overcome these problems, we have immortalized 

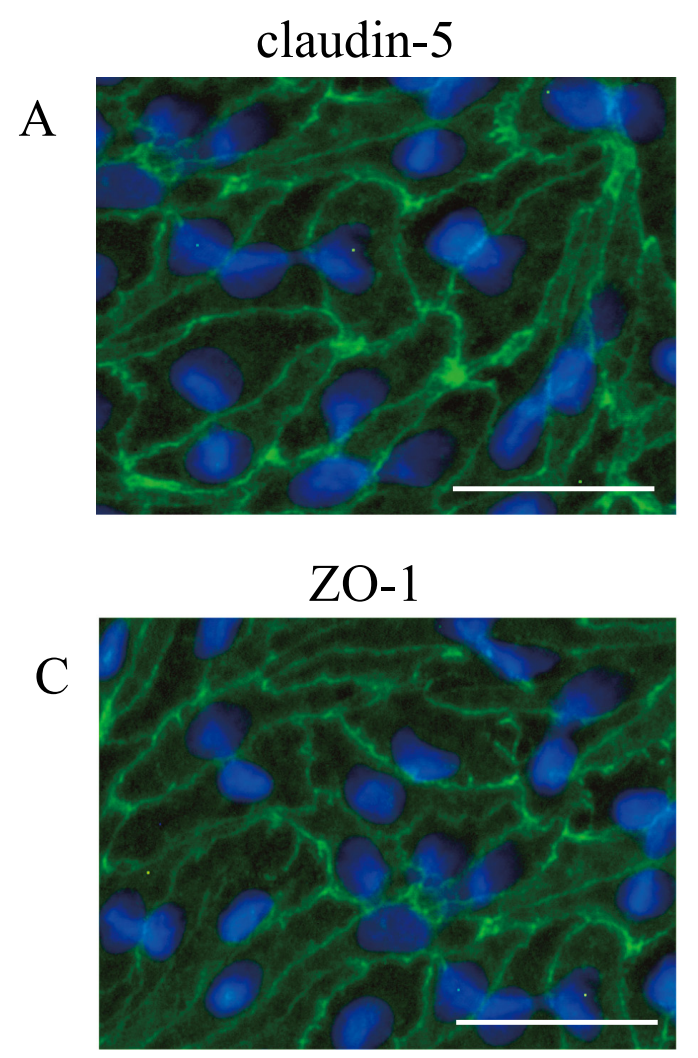
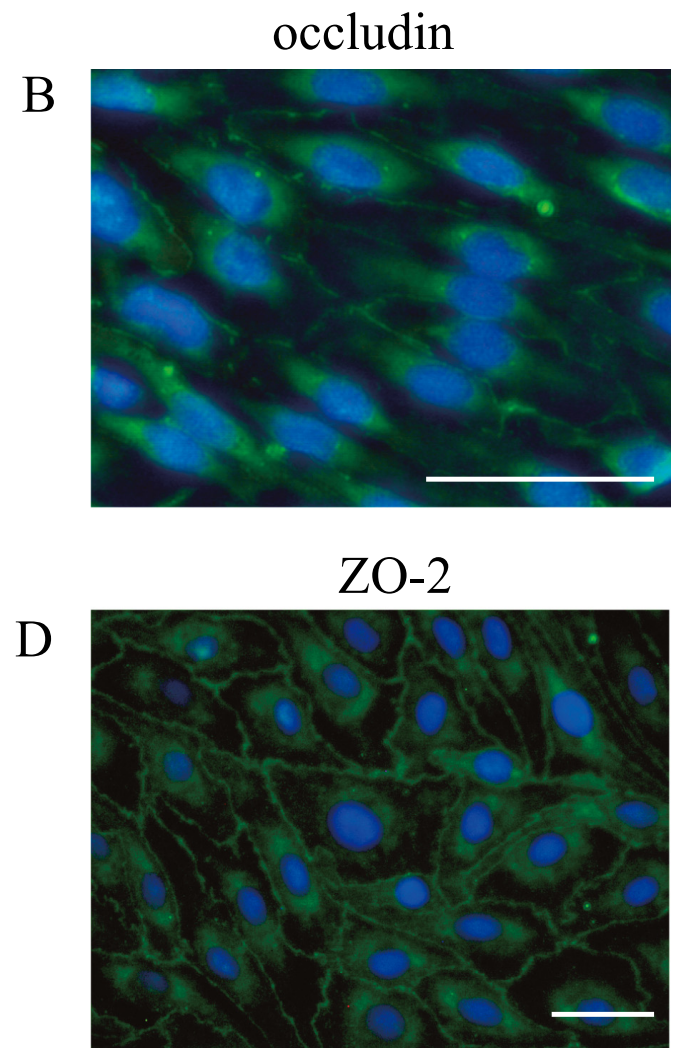

Fig. 4. Immunocytochemical analysis of tight junction proteins in confluent FH-BNBs. Claudin-5 (A), occludin (B), ZO-1 (C) and ZO-2 (D) were continuously detected at the cell-cell boundaries in FH-BNBs. Their nuclei were stained with DAPI (blue). The scale bars indicate $25 \mu \mathrm{m}$.

A

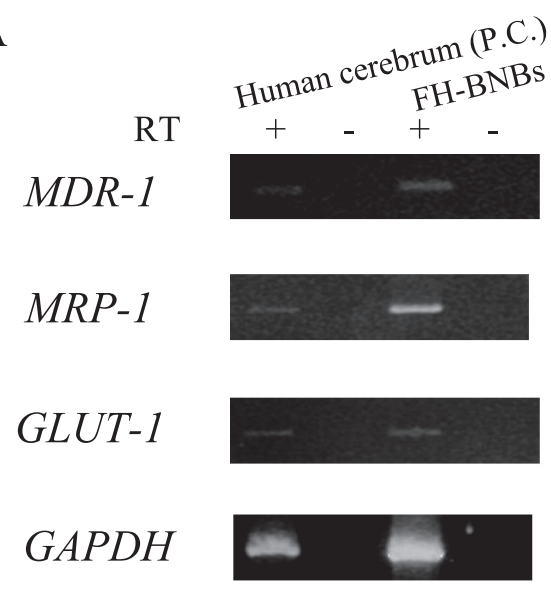

B

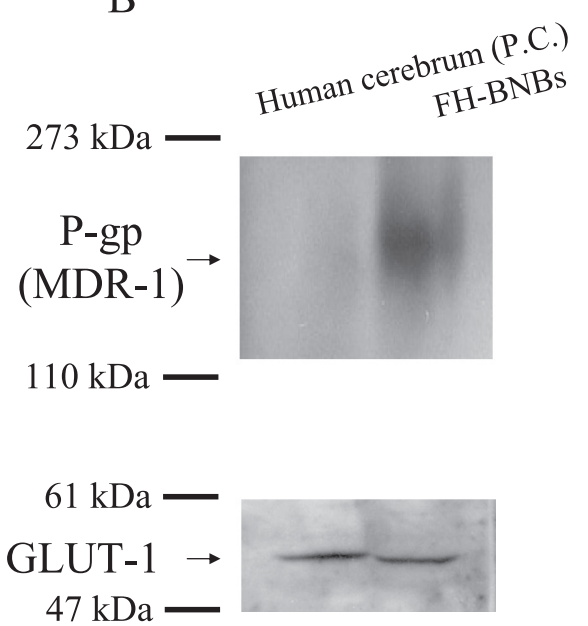

Fig. 5. (A) The expression of transporters in FH-BNBs. G3PDH was used as a control. MDR-1, MRP-1 and GLUT-1 mRNA were all detected in human brain samples as well as in FH-BNBs. The reaction were performed against total RNA with (+) or without (-) RT. (B) The Western blot analysis of the expression of p-gp and GLUT-1 in FH-BNBs. Lane 1, human cerebral cortex as a positive control; Lane 2, FH-BNBs. 
A

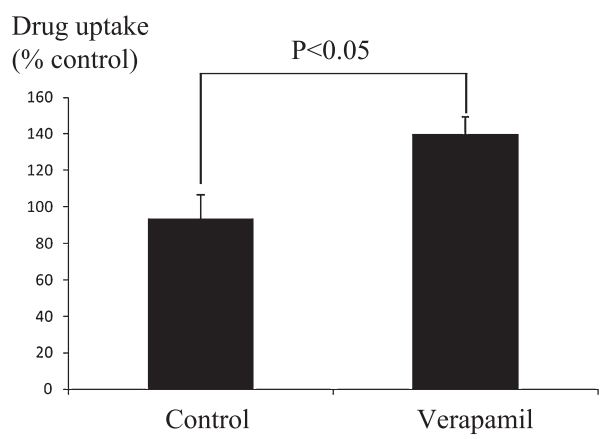

B

CalceinAM

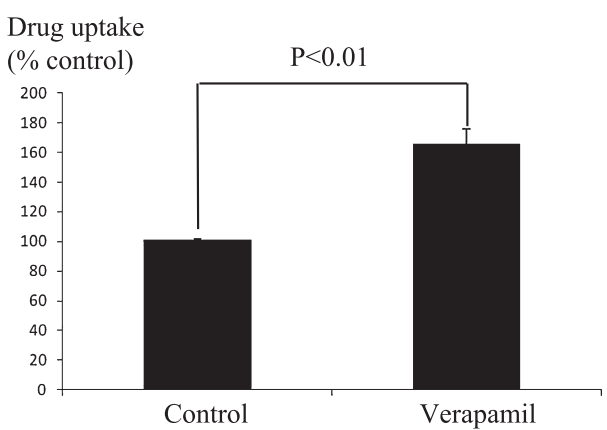

Fig. 6. The result of the p-gp functional assay in FH-BNBs. The cellular uptake of rhodamine123 (A) and calceinAM (B), which are substrates of p-gp was measured in the presence or absence of verapamil, a specific inhibitor of p-gp. The uptake of rhodamine123 and calceinAM in the presence of verapamil was significantly higher than that of control cells without verapamil. The experiments were performed in triplicate. The data are presented as the means and SD.
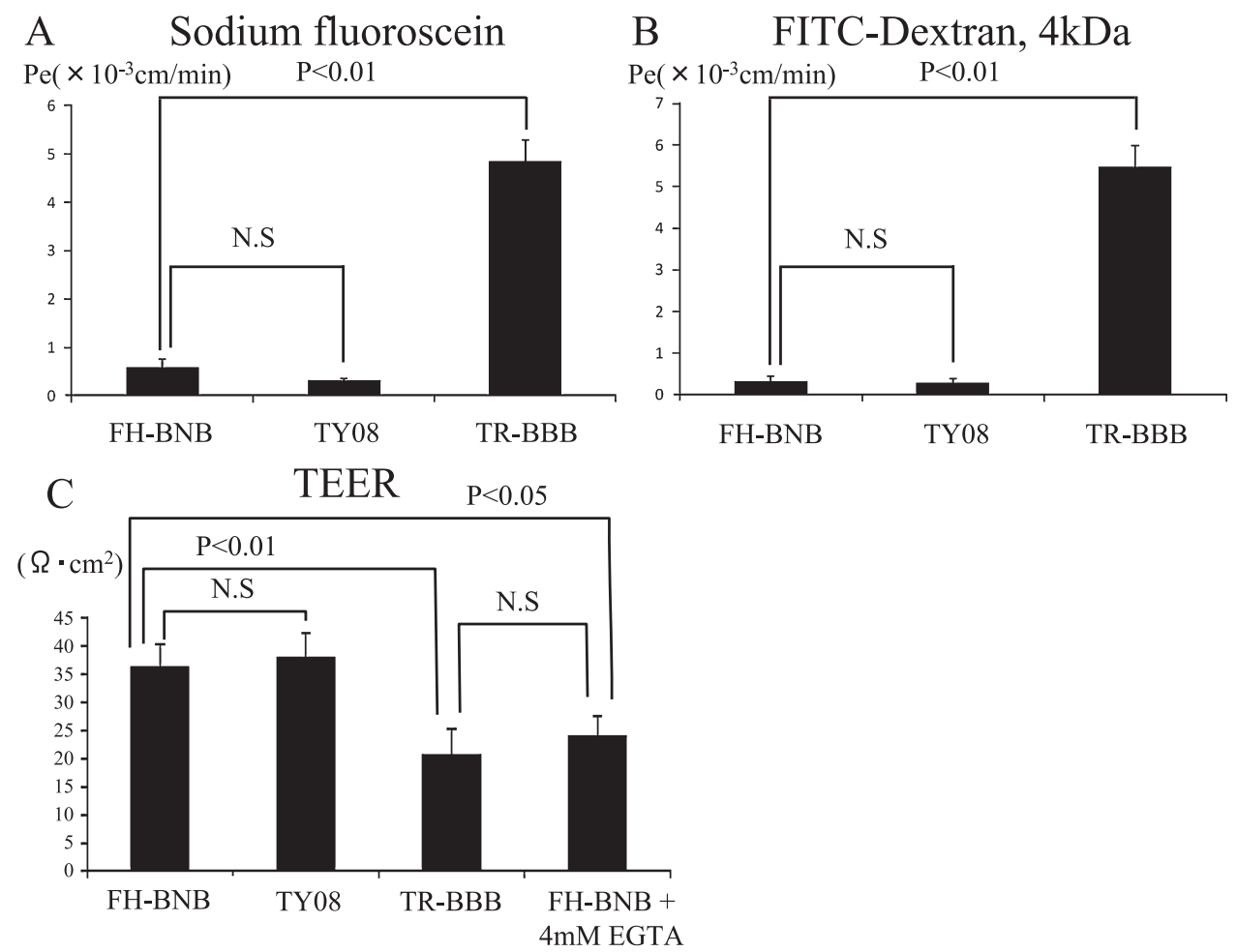

Fig. 7. The paracellular transport of sodium fluorescein (A) and FITC-dextran (B) in FH-BNBs, TY08 cells and the TR-BBBs. The permeability coefficients (Pe) of FH-BNBs for these compounds were as low as those of TY08 cells, and were much lower than those of the TR-BBBs. (C) The transendothelial electrical resistance (TEER) values of the FH-BNBs were as high as those of the TY08 cells, and were higher than those of the TR-BBBs. The TEER values of FH-BNBs incubated with 4 mM EGTA decreaced and became comparable to those of TR-BBBs. The experiments were performed in triplicate. The data are presented as the means \pm SD.

primary human PnMECs a using temperature-sensitive SV 40 large $\mathrm{T}$ antigen (tsA58) and the catalytic subunit of human telomerase (hTERT). FH-BNBs, which express both the hTERT protein and the tsA58 protein, showed a temperature-sensitive nature (Fig. 2E). They grow stably under the permissive temperature of $33^{\circ} \mathrm{C}$ and stop growing under the non-permissive temperature of $37^{\circ} \mathrm{C}$. FH-BNBs showed spindle fiber morphology and contact inhibition even under the permissive temperature of $33^{\circ} \mathrm{C}$, indicating that FH-BNBs, even at the permissive temperature, did not 
develop a tumor-like phenotype.

The endothelial cells forming the BBB express many TJassociated molecules including occludin (Furuse et al., 1993), claudin-1 (Pfeiffer et al., 2011), claudin-5 (Nitta et al., 2003), claudin-12 (Nitta et al., 2003; Ohtsuki et al., 2007), ZO-1, ZO-2 (Biernacki et al., 2004) and JAM-A (Yeung et al., 2008). These molecules compose TJs and limit the paracellular permeability in order to maintain the brain microenvironment. Previous reports have indicated that PnMECs in human sural nerves express occludin, claudin-5 and ZO-1 (Kanda et al., 2004), and claudin-1 was detected in perineurium (Hirakawa et al., 2003), primary human PnMECs (Yosef et al., 2010) and human Schwann cells (Alanne et al., 2009). We also reported that rat PnMECs expressed many molecules forming tight junctions (Sano et al., 2007). FH-BNBs expressed all of the important molecules for maintaining tight junctions at the mRNA level, and contained occludin, claudin-5, ZO-1 and ZO-2 at the cell-cell boundaries at the protein level. Claudin-19 was expressed in human retinal pigment epithelium (Peng et al., 2011) and mouse sciatic nerve and kidney, but not in brain (Miyamoto et al., 2005). Furthermore, claudin-19 existed in peripheral myelinated axons and claudin-19 deficient mice induced peripheral nervous system deficits (Miyamoto et al., 2005). We firstly demonstrated that human PnMECs express claudin-19, indicating that claudin-19 might be a factor to differentiate the endothelial cells of BNB from those of BBB. Trans endothelial permeability studies in $\mathrm{FH}-$ BNBs demonstrated that these cells have a barrier function similar to TY08 cells. Furthermore, the TEER values and permeability to FITC-labeled dextran (MW=4 kDa) were similar to those of hCMEC/D3 cells (TEER $36.3 \pm 4.0$ vs $30-40 \Omega . \mathrm{cm}^{2}$; Pe $0.34 \pm 0.12$ vs $0.325 \times 10^{-3} \mathrm{~cm} / \mathrm{min}$ ), which are human brain microvascular endothelial cell lines that maintain functional tight junctions (Weksler et al., 2005). In the case of sodium fluorescein, the permeability of the FH-BNBs was lower than that of the hCMEC/D3 cells $\left(0.60 \pm 0.16 \times 10^{-3} \mathrm{~cm} / \mathrm{min}\right.$ vs $2.36 \times 10^{-4} \mathrm{~cm} / \mathrm{sec}$ ) (Hsuchou et al., 2010). Consequently, the FH-BNBs were thought to form an effective barrier similar to the BBB forming endothelial cell lines, TY08 and hCMEC/D3 cells. It has been reported that immortalized endothelial cell lines derived from mouse, bovine, rat, porcine BBB show high TEER values (Deli et al., 2005). On the other hand, the TEER of hCMEC/D3 cells and TY08 cells, both of which were derived from human brain, have been reported to be 30-40 ohm $\mathrm{cm}^{2}$ (Weksler et al., 2005; Sano et al., 2010). We think that this discrepancy of the TEER values might result from a species differences. Another considerable point is the problem of purity of the cells. Yosef et al. reported that primary human PnMECs have higher TEER values than FH-BNBs (Yosef et al., 2010). However, these primary cells inevitably contained a small amount of pericytes, which have been reported to promote barrier integrity of the barrier-derived endothelial cells (Shimizu et al., 2011).
Because the purity of FH-BNBs, TY08, and hCMEC/D3 is $100 \%$ and all of these cell lines are derived from humans, we think that FH-BNBs have functional tight junctions as barrier-constituting cells derived from human tissue.

In the brain, $\mathrm{ABC}$ transporters such as p-gp and MRP-1 are mainly localized on the luminal surface of endothelial cells, and quickly remove the toxic metabolites to maintain brain homeostasis (Schinkel et al., 1996). GLUT-1, a Dglucose transporter, is abundantly present on the abluminal surface of endothelial cells forming the BBB. GLUT-1 plays important roles in brain metabolism, since glucose is the main energy source in the brain (Qutub and Hunt, 2005; Simpson et al., 2007). The glucose requirements of peripheral nerves have been also reported to be very high (Greene and Winegrad, 1979). We previously described that the same transporters were expressed in rat PnMECs (Sano et al., 2007). GLUT-1 and p-gp have been demonstrated to present on microvessels in the endoneurium of rat sciatic nerves by an immunohistochemical analysis (Sano et al., 2007). The FH-BNBs in the present study also expressed MDR-1, MRP-1 and GLUT-1. In addition, the functional expression of $\mathrm{p}$-gp was observed in these cells. These results suggest that PnMECs supply D-glucose as an energy source for nerve fibers by using GLUT-1, and protect nerve tissues against toxic substrates with p-gp in the peripheral nervous system.

Recently, primary cultured human PnMECs were isolated and extensively characterized (Yosef et al., 2010). These cells are very useful to analyze the nature of the endothelium forming the BNB; however, they have limited capacities for division because they are not immortalized, and they also contain a small percentage of non-endothelial cells including pericytes and fibroblasts. On the other hand, our FH-BNBs consist of $100 \%$ endothelial cells derived from the BNB and have the ability to grow and maintain their barrier phenotype after at least 30 passages.

In conclusion, the newly established FH-BNBs, which maintain their original nature as endothelial cells forming the BNB will be a useful tool for investigating the biology of the human BNB, and may lead to the development of novel therapies for many autoimmune and other neuropathies.

Acknowledgments. This study was supported in part by research grants (No.21390268, 21790841 and 22790821) from the Japan Society for the Promotion of Science, Tokyo, Japan.

\section{References}

Alanne, M.H., Pummi, K., Heape, A.M., Grenman, R., Peltonen, J., and Peltonen, S. 2009. Tight junction proteins in human Schwann cell autotypic junctions. J. Histochem. Cytochem., 57: 523-529.

Argall, K.G., Armati, P.J., and Pollard, J.D. 1994. A method for the isolation and culture of rat peripheral nerve vascular endothelial cells. Mol. Cell. Neurosci., 5: 413-417.

Biernacki, K., Prat, A., Blain, M., and Antel, J.P. 2004. Regulation of cellular and molecular trafficking across human brain endothelial cells 
by Th1- and Th2-polarized lymphocytes. J. Neuropathol. Exp. Neurol., 63: $223-232$.

Boddingius, J. 1984. Ultrastructural and histophysiological studies on the blood-nerve barrier and perineurial barrier in leprosy neuropathy. Acta Neuropathol., 64: 282-296.

Callahan, M.K., Williams, K.A., Kivisakk, P., Pearce, D., Stins, M.F., and Ransohoff, R.M. 2004. CXCR3 marks CD4+ memory T lymphocytes that are competent to migrate across a human brain microvascular endothelial cell layer. J. Neuroimmunol., 153: 150-157.

Deli, M.A., Abraham, C.S., Kataoka, Y., and Niwa, M. 2005. Permeability studies on in vitro blood-brain barrier models: physiology, pathology, and pharmacology. Cell Mol. Neurobiol., 25: 59-127.

Fuchs, S., Hermanns, M.I., and Kirkpatrick, C.J. 2006. Retention of a differentiated endothelial phenotype by outgrowth endothelial cells isolated from human peripheral blood and expanded in long-term cultures. Cell Tissue Res., 326: 79-92.

Furuse, M., Hirase, T., Itoh, M., Nagafuchi, A., Yonemura, S., Tsukita, S., and Tsukita, S. 1993. Occludin: a novel integral membrane protein localizing at tight junctions. J. Cell Biol., 123: 1777-1788.

Ghassemifar, M.R., Eckert, J.J., Houghton, F.D., Picton, H.M., Leese, H.J., and Fleming, T.P. 2003. Gene expression regulating epithelial intercellular junction biogenesis during human blastocyst development in vitro. Mol. Hum. Reprod., 9: 245-252.

Greene, D.A. and Winegrad, A.I. 1979. In vitro studies of the substrates for energy production and the effects of insulin on glucose utilization in the neural components of peripheral nerve. Diabetes, 28: 878-887.

Hirakawa, H., Okajima, S., Nagaoka, T., Takamatsu, T., and Oyamada, M. 2003. Loss and recovery of the blood-nerve barrier in the rat sciatic nerve after crush injury are associated with expression of intercellular junctional proteins. Exp. Cell Res., 284: 196-210.

Hosoya, K.I., Takashima, T., Tetsuka, K., Nagura, T., Ohtsuki, S., Takanaga, H., Ueda, M., Yanai, N., Obinata, M., and Terasaki, T. 2000. mRna expression and transport characterization of conditionally immortalized rat brain capillary endothelial cell lines; a new in vitro BBB model for drug targeting. J. Drug Target., 8: 357-370.

Hsuchou, H., Kastin, A.J., Tu, H., Joan Abbott, N., Couraud, P.O., and Pan, W. 2010. Role of astrocytic leptin receptor subtypes on leptin permeation across hCMEC/D3 human brain endothelial cells. J. Neurochem., 115: 1288-1298.

Iwasaki, T., Kanda, T., and Mizusawa, H. 1999. Effects of pericytes and various cytokines on integrity of endothelial monolayer originated from blood-nerve barrier: an in vitro study. J. Med. Dent. Sci., 46: 31-40.

Kanda, T., Yoshino, H., Ariga, T., Yamawaki, M., and Yu, R.K. 1994. Glycosphingolipid antigens in cultured bovine brain microvascular endothelial cells: sulfoglucuronosyl paragloboside as a target of monoclonal IgM in demyelinative neuropathy. J. Cell Biol., 126: 235-246.

Kanda, T., Iwasaki, T., Yamawaki, M., and Ikeda, K. 1997. Isolation and culture of bovine endothelial cells of endoneurial origin. J. Neurosci. Res., 49: 769-777.

Kanda, T., Yamawaki, M., Iwasaki, T., and Mizusawa, H. 2000. Glycosphingolipid antibodies and blood-nerve barrier in autoimmune demyelinative neuropathy. Neurology, 54: 1459-1464.

Kanda, T., Numata, Y., and Mizusawa, H. 2004. Chronic inflammatory demyelinating polyneuropathy: decreased claudin-5 and relocated ZO-1. J. Neurol. Neurosurg. Psychiatry, 75: 765-769.

Kashiwamura, Y., Sano, Y., Abe, M., Shimizu, F., Haruki, H., Maeda, T., Kawai, M., and Kanda, T. 2011. Hydrocortisone enhances the function of the blood-nerve barrier through the up-regulation of claudin-5. Neurochem. Res., 36: 849-855.

Lach, B., Rippstein, P., Atack, D., Afar, D.E., and Gregor, A. 1993. Immunoelectron microscopic localization of monoclonal $\mathrm{IgM}$ antibodies in gammopathy associated with peripheral demyelinative neuropathy. Acta Neuropathol., 85: 298-307.
Li, M.W., Mruk, D.D., Lee, W.M., and Cheng, C.Y. 2010. Connexin 43 is critical to maintain the homeostasis of the blood-testis barrier via its effects on tight junction reassembly. Proc. Natl. Acad. Sci. USA, 107: 17998-18003.

Miyamoto, T., Morita, K., Takemoto, D., Takeuchi, K., Kitano, Y., Miyakawa, T., Nakayama, K., Okamura, Y., Sasaki, H., Miyachi, Y., Furuse, M., and Tsukita, S. 2005. Tight junctions in Schwann cells of peripheral myelinated axons: a lesson from claudin-19-deficient mice. J. Cell Biol., 169: 527-538.

Nitta, T., Hata, M., Gotoh, S., Seo, Y., Sasaki, H., Hashimoto, N., Furuse, M., and Tsukita, S. 2003. Size-selective loosening of the blood-brain barrier in claudin-5-deficient mice. J. Cell Biol., 161: 653-660.

O'Hare, M.J., Bond, J., Clarke, C., Takeuchi, Y., Atherton, A.J., Berry, C., Moody, J., Silver, A.R., Davies, D.C., Alsop, A.E., Neville, A.M., and Jat, P.S. 2001. Conditional immortalization of freshly isolated human mammary fibroblasts and endothelial cells. Proc. Natl. Acad. Sci. USA, 98: $646-651$.

Ohtsuki, S., Sato, S., Yamaguchi, H., Kamoi, M., Asashima, T., and Terasaki, T. 2007. Exogenous expression of claudin-5 induces barrier properties in cultured rat brain capillary endothelial cells. J. Cell Physiol., 210: 81-86.

Peng, S., Rao, V.S., Adelman, R.A., and Rizzolo, L.J. 2011. Claudin-19 and the barrier properties of the human retinal pigment epithelium. Invest. Ophthalmol. Vis. Sci., 52: 1392-1403.

Pfeiffer, F., Schafer, J., Lyck, R., Makrides, V., Brunner, S., SchaerenWiemers, N., Deutsch, U., and Engelhardt, B. 2011. Claudin-1 induced sealing of blood-brain barrier tight junctions ameliorates chronic experimental autoimmune encephalomyelitis. Acta Neuropathol., 122: 601614.

Poduslo, J.F., Curran, G.L., and Berg, C.T. 1994. Macromolecular permeability across the blood-nerve and blood-brain barriers. Proc. Natl. Acad. Sci. USA, 91: 5705-5709.

Qutub, A.A. and Hunt, C.A. 2005. Glucose transport to the brain: a systems model. Brain Res. Brain Res. Rev., 49: 595-617.

Sano, Y., Shimizu, F., Nakayama, H., Abe, M., Maeda, T., Ohtsuki, S., Terasaki, T., Obinata, M., Ueda, M., Takahashi, R., and Kanda, T. 2007. Endothelial cells constituting blood-nerve barrier have highly specialized characteristics as barrier-forming cells. Cell Struct. Funct., 32: 139-147.

Sano, Y., Shimizu, F., Abe, M., Maeda, T., Kashiwamura, Y., Ohtsuki, S., Terasaki, T., Obinata, M., Kajiwara, K., Fujii, M., Suzuki, M., and Kanda, T. 2010. Establishment of a new conditionally immortalized human brain microvascular endothelial cell line retaining an in vivo blood-brain barrier function. J. Cell. Physiol., 225: 519-528.

Schinkel, A.H., Wagenaar, E., Mol, C.A., and van Deemter, L. 1996. Pglycoprotein in the blood-brain barrier of mice influences the brain penetration and pharmacological activity of many drugs. J. Clin. Invest., 97: 2517-2524.

Shimizu, F., Sano, Y., Abe, M.A., Maeda, T., Ohtsuki, S., Terasaki, T., and Kanda, T. 2011. Peripheral nerve pericytes modify the blood-nerve barrier function and tight junctional molecules through the secretion of various soluble factors. J. Cell. Physiol., 226: 255-266.

Simpson, I.A., Carruthers, A., and Vannucci, S.J. 2007. Supply and demand in cerebral energy metabolism: the role of nutrient transporters. J. Cereb. Blood Flow Metab., 27: 1766-1791.

Soderfeldt, B. 1974. The perineurium as a diffusion barrier to protein tracers. Influence of histamine, serotonine and bradykinine. Acta Neuropathol., 27: 55-60.

Stins, M.F., Badger, J., and Sik Kim, K. 2001. Bacterial invasion and transcytosis in transfected human brain microvascular endothelial cells. Microb. Pathog., 30: 19-28.

Takahashi, R., Hirabayashi, M., Yanai, N., Obinata, M., and Ueda, M. 1999. Establishment of SV40-tsA58 transgenic rats as a source of conditionally immortalized cell lines. Exp. Anim., 48: 255-261. 
Umeki, N., Fukasawa, Y., Ohtsuki, S., Hori, S., Watanabe, Y., Kohno, Y., and Terasaki, T. 2002. mRNA expression and amino acid transport characteristics of cultured human brain microvascular endothelial cells (hBME). Drug Metab. Pharmacokinet., 17: 367-373.

Varley, C.L., Garthwaite, M.A., Cross, W., Hinley, J., Trejdosiewicz, L.K., and Southgate, J. 2006. PPARgamma-regulated tight junction development during human urothelial cytodifferentiation. J. Cell. Physiol., 208: 407-417.

Voyta, J.C., Via, D.P., Butterfield, C.E., and Zetter, B.R. 1984. Identification and isolation of endothelial cells based on their increased uptake of acetylated-low density lipoprotein. J. Cell Biol., 99: 2034-2040.

Weerasuriya, A. and Rapoport, S.I. 1986. Endoneurial capillary permeability to $[14 \mathrm{C}]$ sucrose in frog sciatic nerve. Brain Res., 375: 150-156.

Weerasuriya, A., Curran, G.L., and Poduslo, J.F. 1989. Blood-nerve transfer of albumin and its implications for the endoneurial microenvironment. Brain Res., 494: 114-121.

Weerasuriya, A. 2005. Blood-Nerve Interface and Endoneurial Homeostasis. Peripheral neuropathy (P.J. Dick and P.K. Thomas, eds.). Elsevier, Philadelphia, pp.651-665.

Weksler, B.B., Subileau, E.A., Perriere, N., Charneau, P., Holloway, K., Leveque, M., Tricoire-Leignel, H., Nicotra, A., Bourdoulous, S., Turowski, P., Male, D.K., Roux, F., Greenwood, J., Romero, I.A., and
Couraud, P.O. 2005. Blood-brain barrier-specific properties of a human adult brain endothelial cell line. FASEB J., 19: 1872-1874.

Yamamoto, K., de Waard, V., Fearns, C., and Loskutoff, D.J. 1998. Tissue distribution and regulation of murine von Willebrand factor gene expression in vivo. Blood, 92: 2791-2801.

Ye, L., Martin, T.A., Parr, C., Harrison, G.M., Mansel, R.E., and Jiang, W.G. 2003. Biphasic effects of 17-beta-estradiol on expression of occludin and transendothelial resistance and paracellular permeability in human vascular endothelial cells. J. Cell. Physiol., 196: 362-369.

Yeung, D., Manias, J.L., Stewart, D.J., and Nag, S. 2008. Decreased junctional adhesion molecule-A expression during blood-brain barrier breakdown. Acta Neuropathol., 115: 635-642.

Yosef, N., Xia, R.H., and Ubogu, E.E. 2010. Development and characterization of a novel human in vitro blood-nerve barrier model using primary endoneurial endothelial cells. J. Neuropathol. Exp. Neurol., 69: 82-97.

Zlokovic, B.V. 2008. The blood-brain barrier in health and chronic neurodegenerative disorders. Neuron, 57: 178-201.

(Received for publication, December 5, 2011, accepted, May 8, 2012 and published online, May 19, 2012) 